\title{
NUEVAS ESPECIES DE LICARIA, OCOTEA Y PERSEA (LAURACEAE) DE MÉXICO
}

\author{
Francisco G. Lorea-HernÁNDEZ \\ Instituto de Ecología, A. C. \\ Apartado postal 63 \\ 91000 Xalapa, Veracruz
}

\begin{abstract}
RESUMEN
Se describen e ilustran ocho especies nuevas de la familia Lauraceae para México, a saber: Licaria phymatosa, L. quercina, L. siphonantha, Ocotea atacta, O. sarcodes, $O$. zoque, Persea chrysantha y $P$. obscura. Las tres especies de Licaria corresponden al subgénero Licaria; $L$. phymatosa es cercana a L. excelsa y L. siphonantha lo es a L. triandra, en tanto que $L$. quercina se relaciona débilmente con $L$. peckii. Ocotea atacta y $O$. zoque pertenecen al grupo de especies relacionadas con $O$. insularis, mientras que la morfología de $O$. sarcodes la ubica en una posición aislada, lejanamente relacionada con el grupo de $O$. heydeana. Los caracteres de Persea chrysantha la aproximan a $P$. hintonii, en tanto que la posición de $P$. obscura es incierta.
\end{abstract}

Palabras clave: Lauraceae, Licaria, México, Ocotea, Persea.

\begin{abstract}
Eight new species of Lauraceae from Mexico are described and illustrated, namely: Licaria phymatosa, L. quercina, L. siphonantha, Ocotea atacta, O. sarcodes, O. zoque, Persea chrysantha and P. obscura. The three Licaria species belong in the subgenus Licaria; $L$. phymatosa and $L$. siphonantha are close to $L$. excelsa and $L$. triandra, respectively, while $L$. quercina is related weakly to $L$. peckii. Both Ocotea atacta and $O$. zoque add to the species related to $O$. insularis, whereas $O$. sarcodes is rather isolated, distantly related to the species of the $O$. heydeana group. Features of Persea chrysantha connect it to $P$. hintonii, but the position of $P$. obscura is uncertain.
\end{abstract}

Key words: Lauraceae, Licaria, Mexico, Ocotea, Persea. 


\section{INTRODUCCIÓN}

La recolección diligente que han realizado varios botánicos en las últimas dos décadas, en particular en el sur de México, ha devenido en el descubrimiento de diversas especies y nuevos registros de plantas para la flora nacional. En el transcurso de una revisión general de los representantes mexicanos de la familia Lauraceae se encontraron varios especímenes, producto de esas prospecciones recientes, que corresponden a algunas especies no descritas que se presentan a continuación.

El reconocimiento de los nuevos taxones se basa en la correlación de varios caracteres, cuya combinación discrepa claramente de la que se encuentra en los otros miembros conocidos de los géneros respectivos. Se espera que algunos rasgos por los que se distingue a estas especies puedan ser identificados posteriormente como sinapomorfias en cada una de ellas.

\section{LOS NUEVOS TAXONES}

Licaria phymatosa Lorea-Hern. sp. nov. Fig. 1.

Tipo. México. Guerrero: mpio. Leonardo Bravo, aprox. $3 \mathrm{~km}$ al NE de Cruz de Ocote, por el camino a Puerto El Gallo, 2260 m, 4 marzo 1984, F. Lorea 2976 (holotipo, XAL, isotipos, FCME, MO).

Arbores; ramulis conspicue lenticellatis, pubescentibus, trichomatibus adpressis; foliis anguste ellipticis vel ellipticis, in apice acutatis vel acuminatis, base cuneatis, interdum obtusis, laminis supra et infra glabris; inflorescentiis paniculatis, plerumque (sub)apicalibus, puberulis; floribus turbinatis, tepalis inaequalibus, externis majoribus, internis minoribus, plerumque extus et intus glabris, staminibus verticillorum I et II carentibus, filamentis verticilli III connatis fere omnino, antheris glabris, sporangiis apicalibus, glandibus manifestis, staminodiis (verticilli IV) plerumque carentibus, hypanthio extus puberulo vel glabrato, intus glabro; fructibus ellipsoideis, cupulis fructuum cyathiformibus, conspicue lenticellatis, pedicellis incrassatis, turbinatis.

Árboles de 15-20(-35) m; ramillas conspicuamente lenticeladas, pubescentes, los tricomas de 0.2-0.3 mm, adpresos, glabras al envejecer; peciolo de (10-)13-20(-26) $\mathrm{x}$ (1.3-)1.6-2(-2.4) mm ligera a conspicuamente acanalado del lado adaxial, glabro; lámina foliar de (7-)11-17(-22) x (2-)3.5-5.5(-7.5) cm, angostamente elíptica o elíptica, ápice agudo a acuminado, base cuneada, a veces obtusa, superficies adaxial y abaxial glabras, vena media plana o algo elevada adaxialmente, glabra, algo 


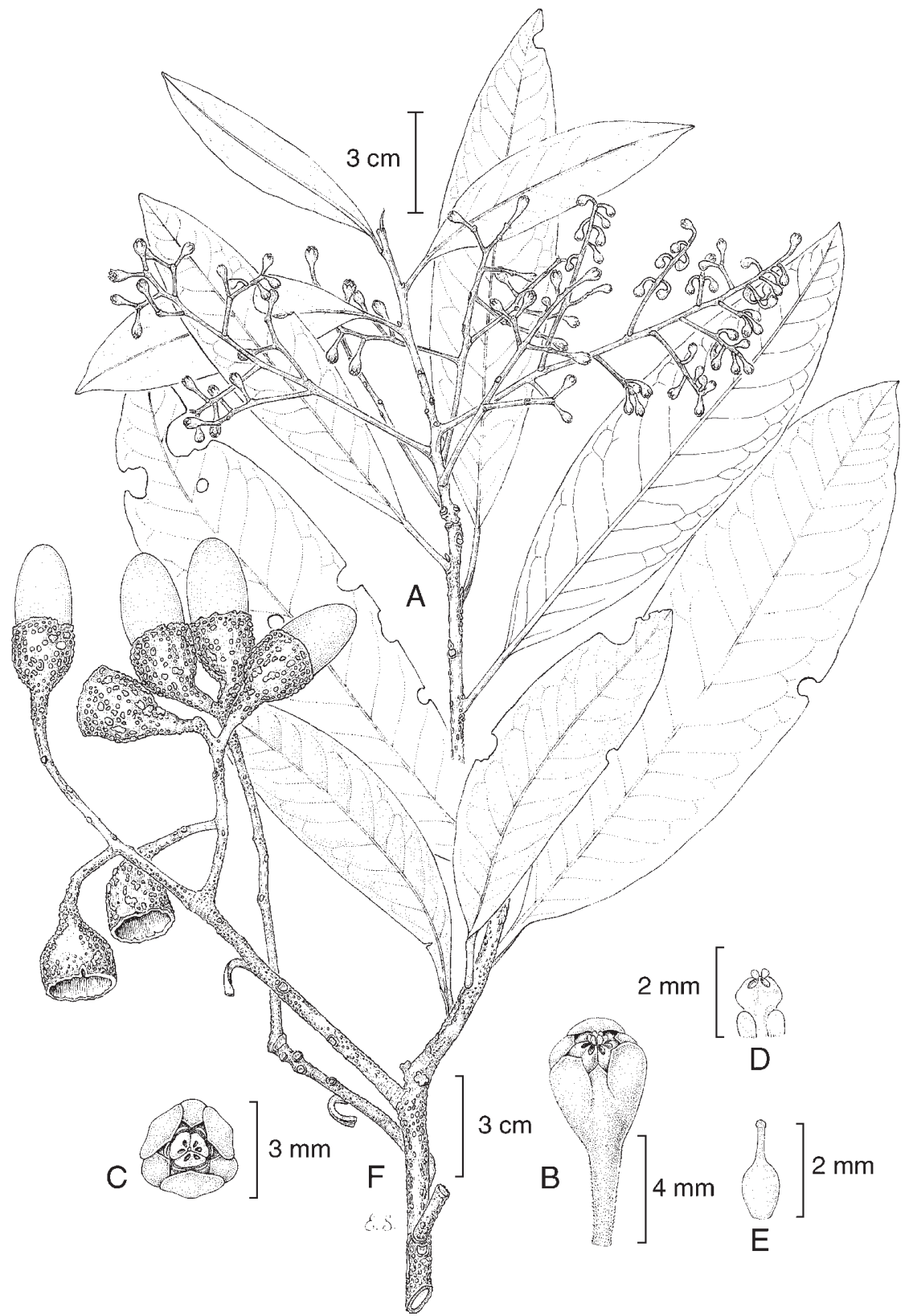

Fig. 1. Licaria phymatosa. A. Ramilla con inflorescencias; B. Vista oblicua de una flor; C. Vista apical de una flor; D. Vista abaxial de un estambre; E. Pistilo; F. Ramilla con frutos. 
elevada abaxialmente, glabra, venas secundarias (13-)15-18(-21) pares, planas y glabras del lado adaxial, débilmente elevadas del abaxial, glabras, venas terciarias planas e imperceptibles en la haz, planas en el envés; inflorescencia de 6-18 cm de largo, terminal o subterminal, rara vez en la axila de brácteas deciduas en la base de los brotes jóvenes, puberulenta, pedúnculo nulo o hasta $3 \mathrm{~cm}$ de largo, pedicelo de (3-)4-5.5(7.5) $\mathrm{mm}$ de largo, puberulento; flores turbinadas, rosadas, los tépalos externos de 1.1-1.5 x 1.6-1.8 mm, (muy) ampliamente ovados, glabros del lado adaxial, glabros o esparcidamente pubescentes del abaxial, los internos de 0.8-1.3 x 1-1.3 mm, ovados a ampliamente ovados, glabros adaxial y abaxialmente, estambres de los verticilos I y II ausentes, estambres del verticilo III de $0.9-1.1 \mathrm{~mm}$ de largo, filamentos pubescentes a glabrescentes del lado adaxial, glabros del abaxial, unidos entre sí en casi toda su longitud, anteras ca. $0.3 \mathrm{~mm}$ de largo, glabras, esporangios dos, apicales, glándulas 0.7-0.9 $\mathrm{mm}$ de largo, oblongas, en la base del filamento, estaminodios del verticilo IV ausentes, ocasionalmente uno o dos presentes pero diminutos $(0.2 \mathrm{~mm})$, hipantio de casi $1.2 \mathrm{~mm}$ de profundidad, puberulento a glabrescente del lado abaxial, glabro del adaxial, pistilo de 2-2.4 mm de largo, glabro, ovario de 1-1.4 x 0.9-1.1 mm; fruto de 21-33 x 16-20 mm, elipsoide, negro cuando maduro, tépalos no persistentes, hipantio agrandado, de 11$16 \mathrm{~mm}$ de largo, de 16-21 mm de diámetro apical y de 5.5-7.5 mm de diámetro basal, ciatiforme, conspicuamente lenticelado, con doble margen, los márgenes poco desarrollados, rojizo, pedicelo engrosado, de 6-12 $\mathrm{mm}$ de largo, de 5.5-7.5 $\mathrm{mm}$ de diámetro apical y de 2.5-4 $\mathrm{mm}$ de diámetro basal, turbinado.

Si bien Licaria phymatosa se encuentra restringida a algunas áreas de la Sierra Madre del Sur, no es rara localmente. Se le encuentra asociada a especies de los géneros Magnolia, Ocotea, Oreopanax, Persea, Prunus y Quercus, en bosque mesófilo de montaña, o en cañadas húmedas dentro del bosque de encino o de pinoencino, entre los (1500-) 1800 y 2300 m s.n.m. Florece en marzo y, al parecer, en la misma época (marzo-abril) maduran los frutos del año anterior.

Paratipos. México. Guerrero: mpio. Chilpancingo, al E de Omiltemi, entre Plan de Potrerillos y La Aguililla, (fr.), G. Lozano 641 (FCME, XAL); Omiltemi, Barranca Potrerillos, (fr.), A. Méndez 238 (FCME, XAL); mpio. Coyuca de Catalán, Las Palancas, (fr.), X. Madrigal 2486 (ENCB, XAL); mpio. Leonardo Bravo, $4 \mathrm{~km}$ adelante de Atlixtac, camino Chichihualco-Filo de Caballos, (fr.), R. M. Fonseca 65 (FCME, XAL); aprox. $3 \mathrm{~km}$ al NE de Cruz de Ocote, (fl., fr.), F. Lorea 3462 (FCME, XAL); $3.5 \mathrm{~km}$ al NE de Cruz de Ocote, (fr.), F. Lorea 5486 (FCME, XAL); $6 \mathrm{~km}$ al $\mathrm{N}$ de Cruz de Ocote, (fl.), M. Millán 119 (FCME, XAL); $6 \mathrm{~km}$ al NE de Cruz de Ocote, (fr.), E. Velázquez 205 (FCME, XAL); $21 \mathrm{~km}$ adelante de Carrizal de Bravo, camino Filo de Caballos-Atoyac, (fr.), J. L. Contreras \& L. Lorenzo 1104 (FCME). 
La morfología de los estambres en Licaria phymatosa la ubica en el subgénero Licaria (Kurz, 2000). A su vez, las flores con tépalos casi libres incurvados, estaminodios de los verticilos I y II ausentes, anteras introrsas con poros apicales y filamentos de los estambres unidos, relacionan a esta especie con L. excelsa Kosterm. Esta última tiene ramillas glabras, usualmente aladas o acostilladas, hojas en promedio mayores $(20-30 \times 6-9 \mathrm{~cm})$, venas secundarias elevadas y evidentes en el envés de la hoja, inflorescencias usualmente con más de 100 flores y flores pardas (en seco); en tanto, L. phymatosa presenta ramillas pubescentes (al menos cuando jóvenes), sin alas o costillas, hojas generalmente menores (11-17 x 3.5-5$5 \mathrm{~cm}$ ), venas secundarias ligeramente elevadas e indistintas en el envés de la hoja, inflorescencias por lo general con 30-50 flores y flores de tonos rosados o rojizos (aun en seco). Las diferencias entre estas dos especies parecerían sutiles, pero la apariencia de los ejemplares de uno y otro taxon es claramente discrepante. El nombre de la entidad nueva hace alusión a la apariencia verrucosa de las ramas y cúpula de los frutos, por el alto número de lenticelas presentes en ellos.

Licaria quercina Lorea-Hern., sp nov. Fig. 2.

Tipo. México. Guerrero: mpio. Mártir de Cuilapan, La Esperanza, reserva campesina, 17²4'02" N, 99¹4'59" W, aprox. 1650 m, 20 diciembre 1997, E. Teyuco 317 (holotipo XAL, isotipo FCME).

Arbores; ramulis dense tomentosis; foliis ellipticis vel anguste ellipticis, in apice acutatis vel acuminatis, base obtusis vel leviter cordatis, interdum obliquis, laminis supra glabris, infra tomentulosis vel glabratis, glaucis; inflorescentiis botryoidibus, tomentosis, axibus valde abbreviatis, floribus ut videtur glomeratis; floribus subglobosis, tepalis leviter inaequalibus, incurvatis, extus tomentosis, intus glabris, staminibus verticilli I sterilibus, digitiformibus vel clavatis, staminibus verticilli II carentibus, filamentis verticilli III basaliter connatis, pubescentibus, antheris glabris, sporangiis apicalibus, glandibus manifestis sed binatim connatis, ut videtur tribus tantum, staminodiis (verticilli IV) carentibus, hypanthio non profundo, extus tomentoso, intus glabro; fructibus ellipsoideis, cupulis fructuum cyathiformibus, rugoso-tuberculatis, pedicellis incrassatis, rugosis.

Árboles de $12 \mathrm{~m}$, tronco de color pardo grisáceo claro, ligeramente rugoso, con pequeñas lenticelas; ramillas lisas, densamente tomentosas, tricomas de 0.2$0.3(-0.4) \mathrm{mm}$ de largo, ascendentes o casi erectos; peciolo de $4-8 \times 1.2-2.2 \mathrm{~mm}$, rollizo o ligeramente plano del lado adaxial, densamente tomentoso, tricomas como en las ramillas; lámina foliar de 6-12.5 x $2.5-5.5 \mathrm{~cm}$, elíptica o angostamente elíptica, base obtusa o ligeramente cordada, a veces oblicua, ápice mayormente 


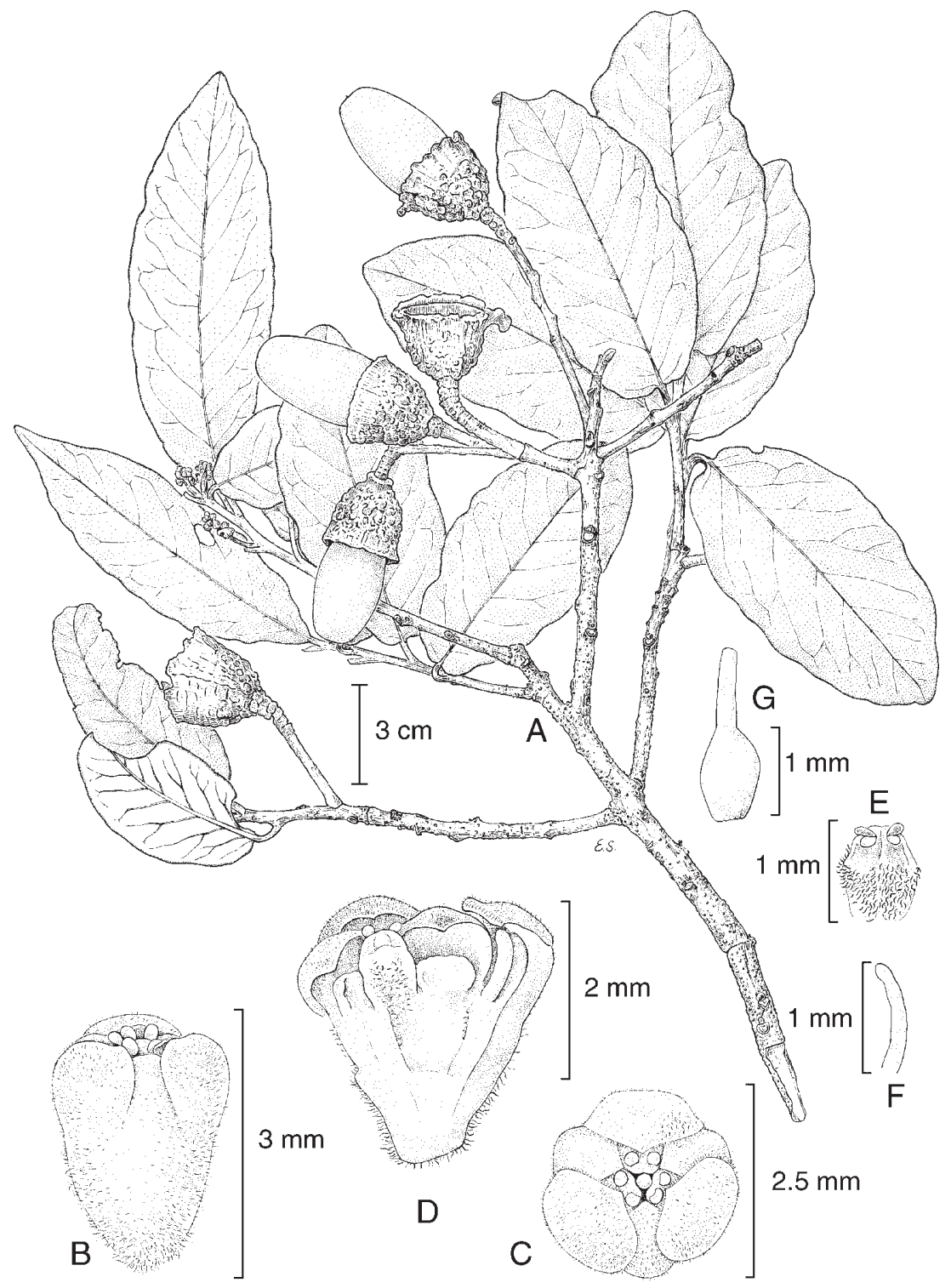

Fig. 2. Licaria quercina. A. Ramilla con flores y frutos; B. Vista lateral de una flor; C. Vista apical de una flor; D. Corte sagital de una flor mostrando un estambre; dos glándulas y un estaminodio; E. Vista abaxial de un estambre; F. Estaminodio; G. Pistilo. 
agudo o a veces acuminado, romo, haz glabra, envés tomentuloso, pronto glabrescente, glauco, vena media plana en su cara adaxial, glabra, elevada abaxialmente, tomentulosa, al menos en su mitad inferior, venas secundarias (9)1113 pares, planas adaxialmente, glabras, algo elevadas del lado abaxial, esparcidamente tomentulosas, venas terciarias planas adaxialmente, glabras, planas abaxialmente, glabrescentes; inflorescencia de ca. $2 \mathrm{~cm}$ de largo, en la axila de las hojas, dibotrioide, con los ejes reducidos, apareciendo las flores casi glomeruladas, pedúnculo de casi $0.7 \mathrm{~cm}$ de largo, densamente tomentoso, los otros ejes de la inflorescencia igualmente tomentosos, pedicelo floral de 5-6(-8) $\mathrm{mm}$ de largo, grueso, turbinado, tomentoso; flores subglobosas, tépalos en dos tamaños, los externos de $1.1 \times 1.6 \mathrm{~mm}$, los internos de $0.9 \times 1.2 \mathrm{~mm}$, todos incurvados, ampliamente ovados, tomentosos por fuera y glabros por dentro, estambres del verticilo I de casi $0.8 \mathrm{~mm}$, estériles (estaminodios), digitiformes o clavados, glabros, estambres del verticilo II ausentes, estambres del verticilo III de 1-1.2 mm de largo, filamentos connados en la base, pubescentes a glabrescentes adaxialmente, vellosos abaxialmente, anteras de $0.5 \mathrm{~mm}$ de largo, glabras, esporangios dos, apicales, glándulas de $0.5 \times 1 \mathrm{~mm}$, presentes como tres grandes estructuras debido a la fusión de glándulas adyacentes de cada estambre, deprimido ovadas, glabras, amarillas pálidas, estaminodios del verticilo IV ausentes, hipantio de casi $0.8 \mathrm{~mm}$ de profundidad, tomentoso por fuera, glabro por dentro, pistilo de $2 \mathrm{~mm}$ de largo, glabro, ovario de $1.2 \times 0.7 \mathrm{~mm}$; fruto de casi $42 \times 22 \mathrm{~mm}$, elipsoidal, asentado en el hipantio agrandado, de casi $20 \mathrm{~mm}$ de largo x $24 \mathrm{~mm}$ de diámetro, ciatiforme, leñoso, irregularmente rugoso tuberculado, tépalos no persistentes en el fruto maduro, pedicelo engrosado, de 5 x 4.5-5.5 mm, leñoso, rugoso.

Licaria quercina hasta ahora se conoce sólo de la localidad tipo y, de acuerdo con la información de los especímenes, crece asociada a algunos árboles del bosque tropical caducifolio, en la zona de contacto con los encinares de Quercus glaucoides, a una altitud cercana a los $1650 \mathrm{~m}$. Flores y frutos presentes en diciembre.

Debido a la disposición y forma de apertura de los esporangios de las anteras, esta especie se ubica también en el subgénero Licaria (Kurz, 2000). La combinación del tipo y distribución de la pubescencia (ramillas tomentosas, envés de las hojas tomentuloso, tépalos tomentosos abaxialmente), así como la morfología de las flores (tépalos incurvados, libres, estambres insertos, unidos por la base de sus filamentos, estaminodios del verticilo I presentes y glándulas del verticilo III fusionadas), no es compartida con ninguna de las especies del área mesoamericana. En cierto modo, Licaria peckii (I. M. Johnst.) Kosterm. se aproxima a L. quercina por sus ramillas y hojas pubescentes, flores de tépalos fuertemente incurvados y estambres insertos; pero difiere de esta última por la pubescencia de sus hojas que está constituida por largos pelos erectos, rectos, y porque en sus flores los tépalos externos están unidos 
en la base, los estambres están unidos a todo lo largo, no hay estaminodios del verticilo I y las glándulas del verticilo III no están fusionadas. La apariencia de las ramillas de esta especie recuerda a las de un encino y de ahí se deriva el epíteto específico. En los datos de los especímenes se anota que localmente es conocida como "encino prieto", confundida seguramente con Quercus glaucoides M. Martens $\&$ Galeotti que crece también en la región.

Licaria siphonantha Lorea-Hern. sp. nov. Fig. 3.

Tipo. México. Guerrero: mpio. Atoyac de Álvarez, aprox. $1.5 \mathrm{~km}$ al W de El Molote, 1720 m, 16 mayo 1993, F. Lorea \& L. Lozada 5532 (holotipo, XAL, isotipos, FCME, MO).

Arbores; ramulis glabris vel puberulis, trichomatibus erectis vel adpressis; foliis anguste ellipticis vel ellipticis, in apice acutatis vel acuminatis, base cuneatis, laminis supra glabris, infra puberulis, trichomatibus adpressis, glabrescentibus; inflorescentiis paniculatis, sessilibus vel pedunculis brevissimis, dense puberulis, axibus terminalibus et subterminalibus valde abbreviatis; floribus tubaeformibus, tepalis aequalibus, minute fimbriatis saltem in parte, extus glabris, intus basaliter pubescentibus, staminibus verticillorum I et II carentibus, filamentis verticilli III connatis, antheris basaliter connatis, sporangiis obliquis, glandibus irregulariter evolutis, claviformibus vel apice distincto, ovoideo vel lunato, staminodiis (verticilli IV) carentibus, hypanthio extus glabro vel puberulo, intus glabro; fructibus ellipsoideis, cupulis fructuum cyathiformibus, margine conspicue duplicato, externo sinuato, leviter extenso, interno integro, erecto, pedicellis leviter incrassatis.

Árboles de 10-15(-20) m; ramillas glabras o puberulentas, tricomas de $(0.1-) 0.3 \mathrm{~mm}$, adpresos y erectos, pronto caedizos; peciolo de (7-)11-14(-17) x 1-1.8 mm, algo acanalado del lado adaxial, puberulento; lámina foliar de (9-)13.5-19(-22) x (2-)3.5$5.5 \mathrm{~cm}$, angostamente elíptica a elíptica, ápice agudo a acuminado, base cuneada, superficie adaxial glabra, adpreso puberulenta abaxialmente, con frecuencia glabrescente al envejecer, vena media plana o débilmente elevada en la base del lado adaxial, glabra, ligeramente elevada del abaxial, adpreso puberulenta, glabrescente con la edad, venas secundarias 12-17 pares, planas y glabras adaxialmente, planas y esparcidamente puberulentas del lado abaxial, venas terciarias con los rasgos de las secundarias; inflorescencias de 3-8(-11.5) cm de largo, axilares a las hojas y terminales, paniculadas, las últimas y penúltimas divisiones fuertemente reducidas, ejes densamente puberulentos, pedúnculo con frecuencia nulo o de hasta $0.5 \mathrm{~cm}$ de largo, pedicelo de (0.2-)0.7-1.2(-1.5) $\mathrm{mm}$, puberulento, los tricomas adpresos y erectos; flores tubulares, color crema a rosado, tépalos de 1-1.2 x 
Lorea-Hernández: Nuevas especies de Lauraceae de México

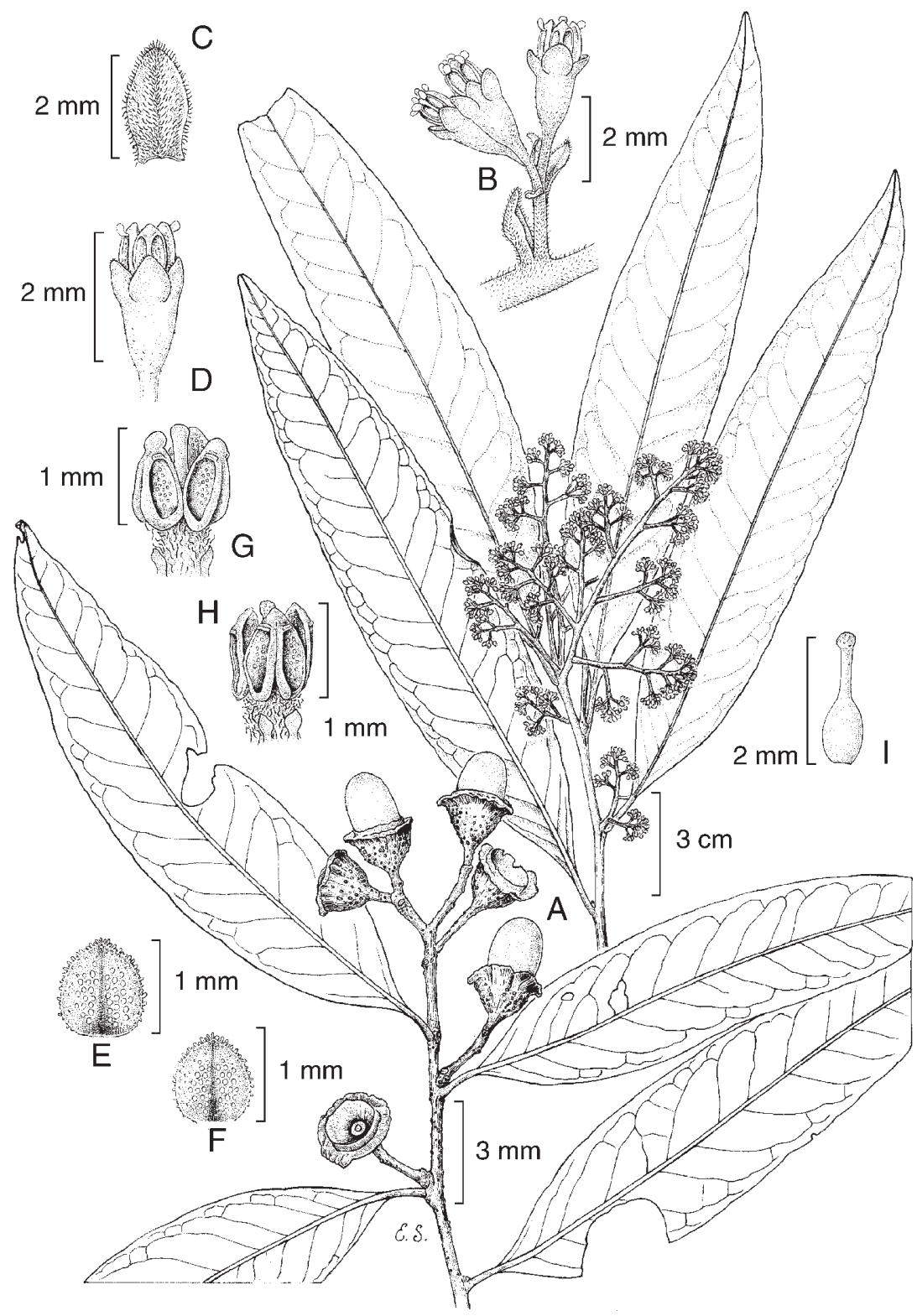

Fig. 3. Licaria siphonantha. A. Ramilla con inflorescencias (arriba) y ramilla con frutos (abajo); B. Detalle de la inflorescencia; C. Vista abaxial de una bráctea; D. Vista lateral de una flor; E. Tépalo externo, vista abaxial; F. Tépalo interno, vista abaxial; G. Vista de los estambres, glándulas y estilo desde un tépalo interno; H. Vista de los estambres, glándulas y estilo desde un tépalo externo; I. Pistilo. 
0.8-1 mm, ovados a ampliamente ovados, todos glabros del lado abaxial y pubescentes sólo en la parte central de la base del lado adaxial, diminutamente fimbriados al menos en parte, estambres de los verticilos I y II ausentes, estambres del verticilo III de 1.6-1.8 mm de largo, filamentos unidos entre sí en toda su longitud, tomentosos a lo largo de la parte media abaxialmente, glabros adaxialmente, anteras de casi $1 \mathrm{~mm}$ de largo, unidas entre sí en su tercio basal, glabras del lado abaxial, esparcidamente tomentosas del adaxial en su mitad basal, esporangios dos, latrorso-extrorsos, glándulas de (0.2-)0.3-0.5 mm de largo, irregularmente desarrolladas, claviformes o con un ápice definido ovoide a lunado, ubicadas en la base del filamento, glabras, estaminodios del verticilo IV ausentes, hipantio de casi $0.6 \mathrm{~mm}$ de profundidad, glabro o adpreso puberulento abaxialmente, glabro adaxialmente, pistilo de 2.2$2.4 \mathrm{~mm}$ de largo, glabro, ovario de casi $0.8 \times 0.6 \mathrm{~mm}$; fruto de $16-18 \times 11$ $12.5 \mathrm{~mm}$, elipsoide, tépalos no persistentes, hipantio agrandado, de $8.5-10.5 \mathrm{~mm}$ de largo, de 15.5-17.5 mm de diámetro apical y de 3.5-4 mm de diámetro basal, ciatiforme, con un doble margen conspicuo, el exterior ondulado y ligeramente extendido, el interior entero y erecto, pedicelo ligeramente engrosado, de $4-5.5 \mathrm{~mm}$ de largo, de 3.5-4 mm de diámetro apical, y de 1.7-2.3 $\mathrm{mm}$ de diámetro basal, turbinado.

Licaria siphonantha es un árbol frecuente en el estrato medio del bosque mesófilo de montaña y del bosque tropical subcaducifolio en la Sierra Madre del Sur, entre los (1000-) 1200 y los $1750 \mathrm{~m}$ de altitud. Florece en la primavera (abrilmayo) y los frutos maduros se encuentran en la misma época del año.

Paratipos. México. Guerrero: mpio. Atoyac de Álvarez, $0.5 \mathrm{~km}$ al W de E1 Molote, (fr.), F. Lorea 3012 (FCME, XAL); (fr.), J. Rojas 29 (FCME, XAL); aprox. $5 \mathrm{~km}$ al S de Nueva Delhi, camino Atoyac-Puerto El Gallo, (fl.), F. Lorea \& L. Lozada 5547 (FCME, XAL); $2 \mathrm{~km}$ adelante del entronque a El Edén, camino Atoyac-Puerto El Gallo, (fr.), R. M. Fonseca 519 (FCME, XAL).

Igual que las especies anteriores, Licaria siphonantha pertenece al subgénero Licaria (Kurz, 2000). Los miembros de este subgénero con flores más o menos cilíndricas y de tépalos libres se encuentran en Sudamérica, y las que comparten (L. multiflora (Kosterm.) Kosterm. y L. oppositifolia (Nees) Kosterm.) otras características con L. siphonantha (v. gr. estambres unidos, glándulas libres), se apartan claramente por otros rasgos; tanto L. multiflora como L. oppositifolia tienen flores con tépalos pubescentes abaxialmente y el ovario también es pubescente, además, en ambas el envés foliar es claramente pubescente y el número de venas secundarias en las hojas es menor a 10 pares. De las especies del área centroamericana, L. triandra (Sw.) Kosterm. (sensu Kurz, 2000) es la que se asemeja más a L. siphonantha; sin embargo, aquella presenta hojas glabras con 
hasta 10 pares de venas secundarias, flores triquetras con tépalos basalmente unidos y glándulas del tercer verticilo bien desarrolladas y usualmente unidas. En tanto, L. siphonantha tiene hojas persistentemente (aunque no de manera conspicua) pubescentes en el envés, con 12 a 17 pares de venas, flores cilíndricas con tépalos glabros, libres, y glándulas del tercer verticilo libres y mediocres. De la apariencia tubular de las flores se deriva el nombre de esta nueva especie.

Ocotea atacta Lorea-Hern. sp. nov. Fig. 4.

Tipo. México. Guerrero: mpio. Chilpancingo, orillas del Río Apetlanca, en dirección al paraje La Escalera, 600 m, 1 mayo 1988, H. Flores 336 (holotipo, XAL, isotipo, FCME).

Arbores; ramulis sericeis, trichomatibus plus minusve persistentibus; foliis ellipticis vel anguste ellipticis, in apice acutatis vel acuminatis, base cuneatis vel anguste cuneatis, marginibus decurrentibus, laminis supra glabris, infra appresse pubescentibus, domatiis praesentibus ad axillas venarum secundariarum, ad margines pubescentibus; inflorescentiis thyrsoideis, sed axibus centralibus ramificationum inflorescentiae ultra primam divisionem axium secundariorum pro parte maxima abortivis, pedunculis et rachidibus glabrescentibus, ceteris axibus pubescentibus; floribus campanulatis, bisexualibus, tepalis aequalibus, extus adpresse puberulis, intus sericeis vel puberulis, staminibus pubescentibus similibus illis $O$. insularis, staminodiis plerumque clavatis, hypanthio intus glabrato, pistillo glabro; fructibus ellipsoideis, cupulis fructuum crateriformibus, pedicellis accrescentibus, incrassatis.

Árboles de 15-25(-35) m; ramillas cortamente seríceas, tricomas de 0.1-0.2 mm, más o menos persistentes, corteza pardo rojiza; peciolo de (6-)9-15(-18) x 1.1$1.5(-2) \mathrm{mm}$, levemente acanalado adaxialmente, pubescente de igual manera que las ramillas, sobre todo en su cara adaxial; lámina foliar de (8-)11-16(-19) x (2-)3.5$5 \mathrm{~cm}$, elíptica a angostamente elíptica, en ocasiones oblanceolada, ápice agudo a acuminado, base cuneada a angostamente cuneada, con los bordes ligeramente reflejos, margen decurrente hacia el peciolo, superficie adaxial glabra, la abaxial adpreso pubescente, con frecuencia glabrescente al envejecer, vena media plana en toda su extensión o levemente hundida en la base adaxialmente, glabra, elevada abaxialmente, adpreso pubescente, sobre todo hacia los márgenes, venas secundarias 11-14(-16) pares, planas y glabras del lado adaxial, ligeramente elevadas y esparcidamente adpreso pubescentes del abaxial, venas terciarias planas y glabras adaxial y abaxialmente o glabrescentes abaxialmente, domacios presentes en la axila de las venas secundarias, por lo menos hasta la mitad de la hoja, elípticos, ligeramente hundidos, con bordes pubescentes, los tricomas de $0.5 \mathrm{~mm}$, extendidos 


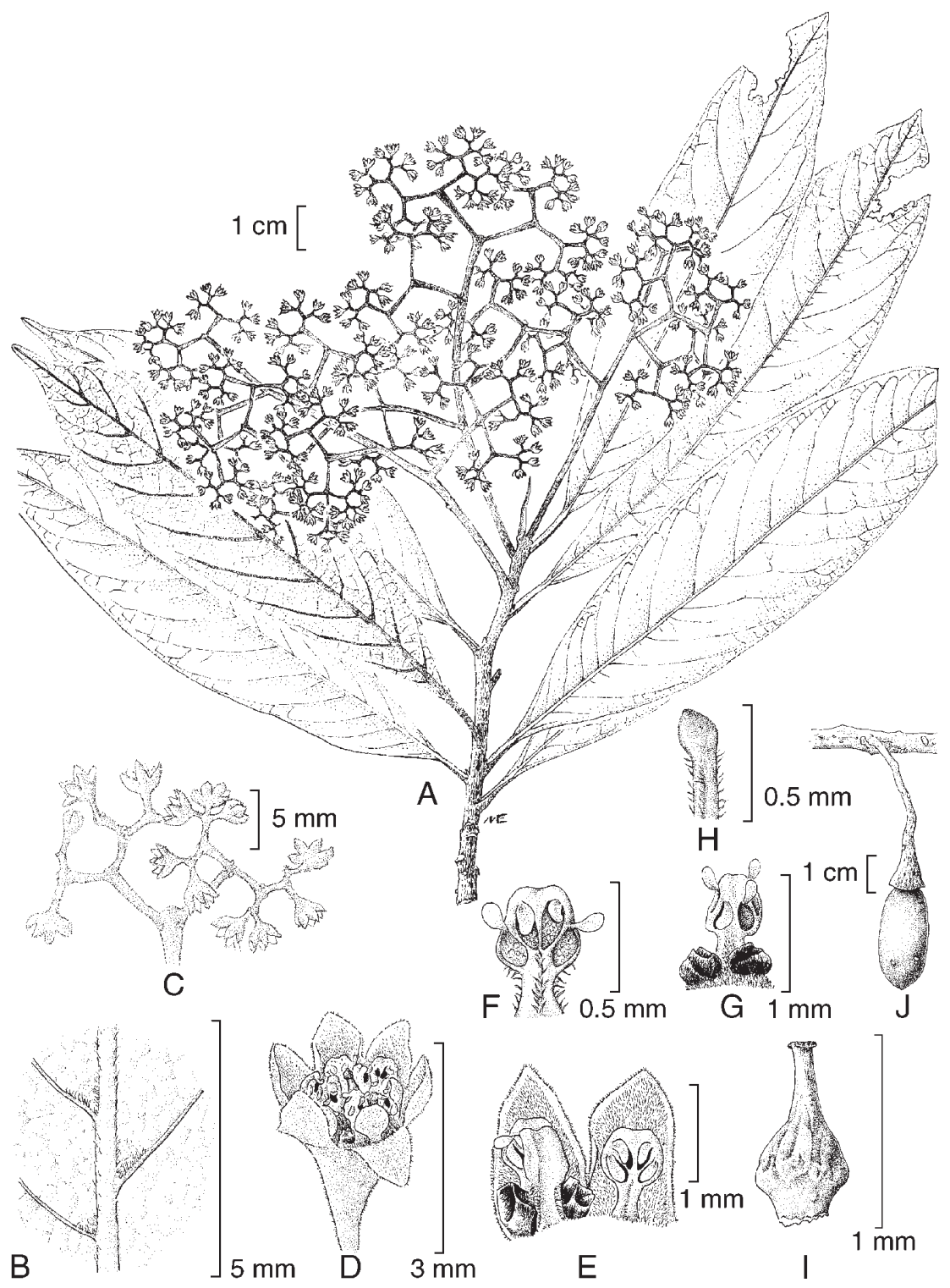

Fig. 4. Ocotea atacta. A. Ramilla con inflorescencias; B. Detalle de la vena media y axilas de las venas secundarias desde el envés; C. Detalle de la inflorescencia; D. Vista oblicua de una flor; E. Vista adaxial de un par de tépalos y sus estambres correspondientes; F. Vista adaxial de un estambre externo; G. Vista abaxial de un estambre interno; H. Estaminodio; I. Pistilo; J. Fruto. 
$\mathrm{u}$ oblicuos, dirigidos hacia el borde opuesto; inflorescencias de (3.5-)7-10 cm, axilares, tirsoides, pero la mayoría de los ejes centrales de las ramificaciones de la inflorescencia abortados después de la primera división de los ejes secundarios, ejes terciarios y subsecuentes comprimidos, pedúnculo y raquis glabrescentes, los demás ejes pubescentes, los tricomas adpresos o ligeramente extendidos, pedúnculo de (1.5-)2.5-4.5 cm, pedicelo de 0.8-1.4(-1.8) $\mathrm{mm}$, densamente pubescente; flores campanuladas, hermafroditas, tépalos de 1.6-1.9 x 1-1.5 mm, los externos elípticos, densamente adpreso puberulentos del lado abaxial, seríceos a puberulentos del adaxial, los internos ovados, pubescentes de igual manera que los externos, estambres de los verticilos I y II de 0.9-1.1 mm, filamentos puberulentos homogéneamente o sólo a lo largo de la parte media o glabros adaxialmente, esparcida a densamente puberulentos abaxialmente, anteras de casi $0.7 \mathrm{~mm}$, glabras excepto la base del conectivo adaxial y abaxialmente, esporangios cuatro, introrsos, estambres del verticilo III de 1.1-1.3 mm, filamentos puberulentos en los márgenes adaxialmente, esparcida a densamente puberulentos abaxialmente, anteras de casi $0.7 \mathrm{~mm}$, glabras excepto una corta línea de tricomas a cada lado de la base adaxialmente, esporangios cuatro, los basales extrorsos, los superiores latrorsos, glándulas de casi $0.4 \mathrm{~mm}$, en la base del filamento, glabras, petriformes, estaminodios del verticilo IV de (0.2-)0.5-0.7 mm, claviformes o con el ápice ovoide, ligeramente más ancho que el filamento, filamento glabro adaxialmente, pubescente abaxialmente, ápice glabro, hipantio de casi $0.5 \mathrm{~mm}$ de profundidad, densamente puberulento del lado abaxial, glabrescente del adaxial, pistilo de $1.7-2 \mathrm{~mm}$, ovario de ca. 1 x $0.9 \mathrm{~mm}$, glabro; fruto de 21-25 x 12-16 mm, elipsoide, tépalos no persistentes, deciduos como una unidad al comienzo del desarrollo, hipantio débilmente agrandado, de $2 \times 5.5-7 \mathrm{~mm}$, crateriforme, pedicelo de 7-10 $\mathrm{mm}$ de largo, de 5-6.5 $\mathrm{mm}$ de ancho apicalmente y de 2.2-3 $\mathrm{mm}$ de diámetro en la base, acrescente, engrosado, turbinado.

Ocotea atacta habita en el bosque tropical subcaducifolio y el bosque mesófilo de montaña, entre los 600 y los $1650 \mathrm{~m}$ de altitud. Florece y tiene frutos maduros en la primavera (mayo).

Paratipos. México. Guerrero: mpio. Atoyac de Álvarez, aprox. $2.5 \mathrm{~km}$ al S de El Molote, por la vereda que va a El Edén, (fr.), F. Lorea \& L. Lozada 5546 (FCME, XAL). Oaxaca: mpio. Pluma Hidalgo, aprox. $400 \mathrm{~m}$ en línea recta al NE de Finca Vista Hermosa, por el camino que va a Corrida Los Pocitos, (fl.), C. Gallardo 2432 (XAL); (fr.), C. Gallardo 2433 (XAL).

El tipo y singular distribución de la pubescencia en los estambres, particularmente en el verticilo III, así como la morfología de la inflorescencia (ejes comprimidos), ubican sin lugar a dudas a $O$. atacta en el grupo de $O$. insularis 
(Meissn.) Mez (Rohwer, 1986; van der Werff, 2002a). De este conjunto se conocen tres especies en México, a saber: $O$. chiapensis (Lundell) Standl. \& Steyerm., $O$. laetevirens Standl. \& Steyerm. y O. rovirosae Lorea-Hern. \& van der Werff (conforme al concepto amplio de van der Werff (2002a)). La pubescencia erecta en las hojas e inflorescencias, el margen basal plano de las hojas, aunado a la ausencia de domacios en $O$. rovirosae separan claramente a esta planta de $O$. atacta. De las otras dos especies, $O$. atacta se diferencia como sigue: $O$. chiapensis tiene domacios cuya superficie foliar es plana, la base de la hoja es revoluta y extensa y conspicuamente decurrente en el peciolo, apareciendo éste comprimido, a su vez, todos los ejes (secundarios y terciarios) de la inflorescencia se desarrollan normalmente; en O. laetevirens la sección laminar de los domacios también es plana, la base de la hoja no es revoluta, e igualmente todas las ramificaciones de la inflorescencia se desarrollan de manera normal, siendo además las flores casi glabras. En tanto, $O$. atacta tiene domacios que están ligeramente hundidos en el tejido foliar, la base de la hoja es leve pero conspicuamente revoluta, el peciolo es evidente aunque algo marginado en la parte distal, la mayoría de los ejes centrales de las ramificaciones de la inflorescencia no se desarrollan después de la primera división de los ejes secundarios y las flores son conspicuamente pubescentes. Cabe enfatizar que la apariencia de la estructura de la inflorescencia deriva, no de la caída de las flores maduras al centro de cada dicasio, sino de la supresión del desarrollo de los ejes (secundarios y terciarios) más allá de su primera ramificación, quedando sólo la sección más basal de cada uno de ellos; los dicasios terminales, sin embargo, son por lo común completos. Del aspecto desordenado que tiene el arreglo de las flores en la inflorescencia deriva el nombre de esta especie.

Ocotea sarcodes Lorea-Hern. sp. nov. Fig. 5.

Tipo. México. Oaxaca: dto. Teotitlán, $32 \mathrm{~km} \mathrm{NE}$ of Teotitlán del Camino on road to Huautla de Jiménez, 2260 m, 7 noviembre 1983, D. Breedlove \& F. Almeda 59870 (holotipo, CAS, isotipos, MEXU, MO, XAL).

Arbores; ramulis glabris; foliis chartaceis, ellipticis vel anguste ellipticis, in apice acutatis vel acuminatis, base cuneatis, laminis supra et infra glabris, pinnatinervibus, domatiis carentibus; inflorescentiis thyrsoideis, glabris; floribus rotatis, bisexualibus, tepalis leviter inaequalibus, externis brevibus, internis longis, extus glabris, intus tomentosis, in apice (plus minusve) lanatis, staminibus novem, illis tertii verticilli latrorsis, staminodiis manifestis, apicibus ovatis, acuminatis, filamentis brevissimis, hypanthio non profundo, intus glabro, pistillo glabro; fructibus ellipsoideis, cupulis fructuum crateriformibus, pedicellis accrescentibus, incrassatis. 


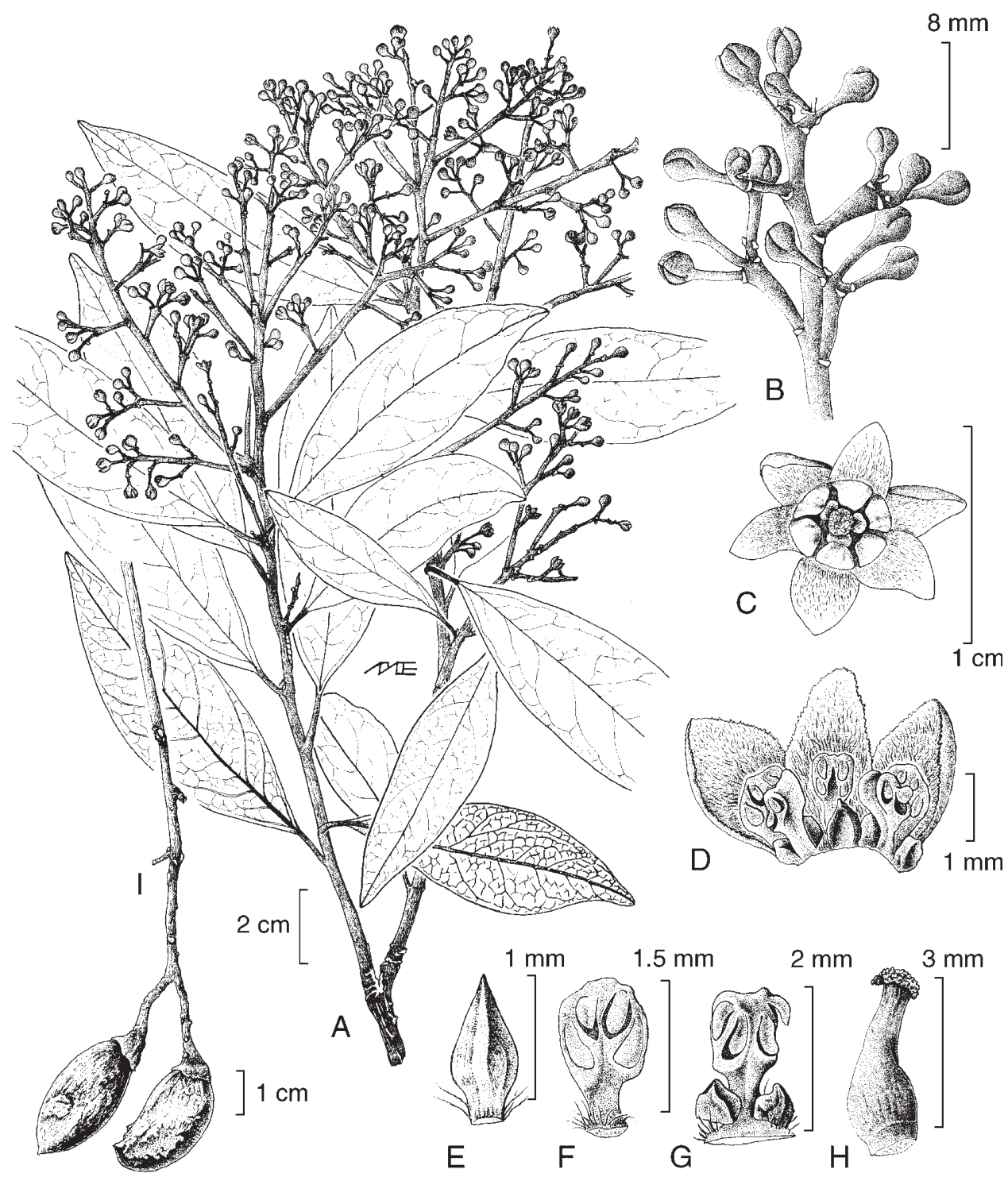

Fig. 5. Ocotea sarcodes. A. Ramilla con inflorescencias; B. Detalle de una inflorescencia; C. Vista apical de una flor; D. Vista interior de una flor; E. Vista abaxial de un estaminodio; F. Vista adaxial de un estambre externo; G. Vista abaxial de un estambre interno; H. Pistilo; I. Frutos. 
Árboles de 15-20 m; ramillas lisas a ligeramente fisuradas, glabras; peciolo de (6-)10-14 x 1.3-2 mm, redondeado abaxialmente, canaliculado adaxialmente (marginado); lámina foliar de (4.5-)8-14(-17.5) x (1.5-)3-5.5 cm, gruesa, cartácea, elíptica o angostamente elíptica, rara vez oblanceolada, ápice agudo a acuminado, base cuneada, glabra en la haz y el envés, vena media plana del lado adaxial, glabra, elevada del abaxial, glabra, venas secundarias (5-)6-8(-9) pares, planas del lado adaxial, glabras, algo elevadas del abaxial, venas terciarias planas y glabras adaxial y abaxialmente, domacios ausentes; inflorescencias de 4-10 $\mathrm{cm}$ de largo, axilares en las hojas o en pequeñas brácteas cerca de la punta de las ramas, semejando entonces una inflorescencia terminal más grande, tirsoides, glabras, pedúnculo nulo o hasta de $2.5 \mathrm{~cm}$ de largo, pedicelo de (2.5-)3-4(-5) $\mathrm{mm}$ de largo; flores rotadas, amarillas pálidas, hermafroditas, los tépalos externos de 3.3-3.8 x 3.2-3.4 mm, los internos de 4.5-4.8 x 3.5-3.7 mm, ovados (todos) a elípticos (los internos), glabros por fuera, los externos tomentosos por dentro sobre todo hacia la parte media o en la base, los internos densamente tomentosos por dentro en toda su superficie, todos con el ápice y borde superior más o menos lanoso, estambres de los verticilos I y II de 2.3-2.5 mm de largo, filamento glabro, excepto su base esparcidamente vellosa del lado adaxial, anteras de 1.4-1.6 mm de largo, glabras, esporangios cuatro, introrsos, estambres del verticilo III de 2.2-2.5 mm de largo, filamento glabro, excepto su base esparcidamente vellosa del lado abaxial, anteras de 1.3-1.4 mm de largo, glabras, esporangios cuatro, los superiores latrorsos, los inferiores latrorsos o ligeramente extrorsos, glándulas de casi $0.8 \mathrm{~mm}$ de diámetro, ubicadas a un lado de la base del filamento, petriformes, glabras, estaminodios de 1.7-1.8 $\mathrm{mm}$ de largo, filamento esparcidamente velloso en los márgenes y adaxialmente, glabro abaxialmente, ápice de 1.3-1.5 $\mathrm{mm}$ de largo, ovado, acuminado, cóncavo adaxialmente, aquillado abaxialmente, glabro, hipantio de casi $0.7 \mathrm{~mm}$ de profundidad, glabro por fuera y por dentro, en ocasiones esparcidamente velloso en el borde superior del lado interno, pistilo de casi $3.5 \mathrm{~mm}$ de largo, ovario de 1.8$2 \mathrm{x}$ ca. $1.3 \mathrm{~mm}$, glabro, estigma de $1.3-1.5 \mathrm{~mm}$ de diámetro, discoidal; fruto de $26-$ $30 \times 15-18 \mathrm{~mm}$, elipsoide, hipantio ligeramente acrescente, de 5-6 x 9-11 mm, crateriforme, tépalos marcescentes, su base por lo general persistente, dando al borde de la cúpula un aspecto sinuoso, pedicelo engrosado, de 8-10 $\mathrm{mm}$ de largo, de casi $2.5 \mathrm{~mm}$ de ancho en la base y de 5-6 $\mathrm{mm}$ de ancho en el ápice, obpiramidal.

Los encinares húmedos y el bosque mesófilo de montaña, entre los 1620 y los $2500 \mathrm{~m}$ de altitud, son el hábitat natural de Ocotea sarcodes. Lo acompañan en el estrato arbóreo varias especies de Quercus, además de los géneros Alfaroa, Clethra, Engelhardtia, Oreopanax y Persea, entre otros. Florece en diciembre y enero, y presenta frutos maduros de fines de noviembre a enero. 
Paratipos. México. Oaxaca: mpio. San Felipe Usila, $8.1 \mathrm{~km}$ en línea recta al S de Santa Cruz Tepetotutla, (fl.), C. Gallardo, J. Meave, L. Lozada \& A. Otero 894 (XAL), $9.1 \mathrm{~km}$ al SE de Santa Cruz Tepetotutla, (fr.), A. Rincón, J. Meave, C. Gallardo, F. Lorea \& X. Munn 783 (XAL), $5.6 \mathrm{~km}$ al SE de Santa Cruz Tepetotutla, J. Meave, N. Velázquez, S. Mendoza, J. Gaxiola \& B. Osorio 1953 (XAL); mpio. Santiago Comaltepec, $2.8 \mathrm{~km}$ en línea recta al SSW de La Esperanza, (fl.), A. Rincón, C. Gallardo \& G. Ibarra 545 (XAL).

La ausencia de indumento en todas las partes vegetativas, las inflorescencias y flores (externamente), las flores grandes, rotadas, y la consistencia gruesa de las hojas (de la que se deriva el nombre de la especie), distingue a $O$. sarcodes de cualquiera de los otros miembros de Ocotea del sur de México y en general de Mesoamérica. Debido a sus características, su posición es más bien aislada y no es claro con qué especie(s) del género se relaciona. El grupo al que podría estar más cercana es el de O. heydeana (Mez \& Donn. Sm.) Bernardi (Rohwer, 1991), particularmente con O. magnifolia (Lundell) Lundell y O. platyphylla (Lundell) Rohwer, las cuales tienen partes vegetativas glabrescentes a glabras y flores grandes, glabras externamente y rotadas. Las diferencias principales estriban en la pubescencia que presentan internamente los tépalos y los estambres de sus flores; ambas tienen tépalos papilosos adaxialmente, en tanto $O$. magnifolia presenta estambres papilosos en las anteras y $O$. platyphylla los tiene glabros o ligeramente papilosos. El punto interesante es que $O$. sarcodes presenta una especie de pubescencia lanosa (pelos ondulados, más o menos entrelazados) en la parte superior de la cara interna de los tépalos, que de ser más corta parecería del tipo papiloso, semejante al de las especies comentadas.

Ocotea zoque Lorea-Hern. sp. nov. Fig. 6.

Tipo. México. Oaxaca: mpio. San Miguel Chimalapa, $9.9 \mathrm{~km}$ en línea recta al NW de San Antonio, 16 42'8.7' N, 94'16'32.4" W, 1640 m, 22 julio 2001, C. Gallardo, N. Velázquez, Z. Garnica, R. López \& P. Gutiérrez 2627 (holotipo, XAL).

Arbores; ramulis dense pubescentibus vel tomentosis, trichomatibus ochraceis; foliis ellipticis, in apice acutatis vel acuminatis, base attenuatis, marginibus leviter sed manifeste involutis ad basim, laminis supra glabris, infra sericeis, leviter glaucis, domatiis carentibus; inflorescentiis thyrso-paniculatis, dense pubescentibus vel tomentosis, trichomatibus ochraceis; floribus rotatis, bisexualibus, tepalis plus minusve aequalibus, extus et intus dense pubescentibus, staminibus pubescentibus similibus illis $O$. insularis, staminodiis claviformibus, plerumque uno tantum 

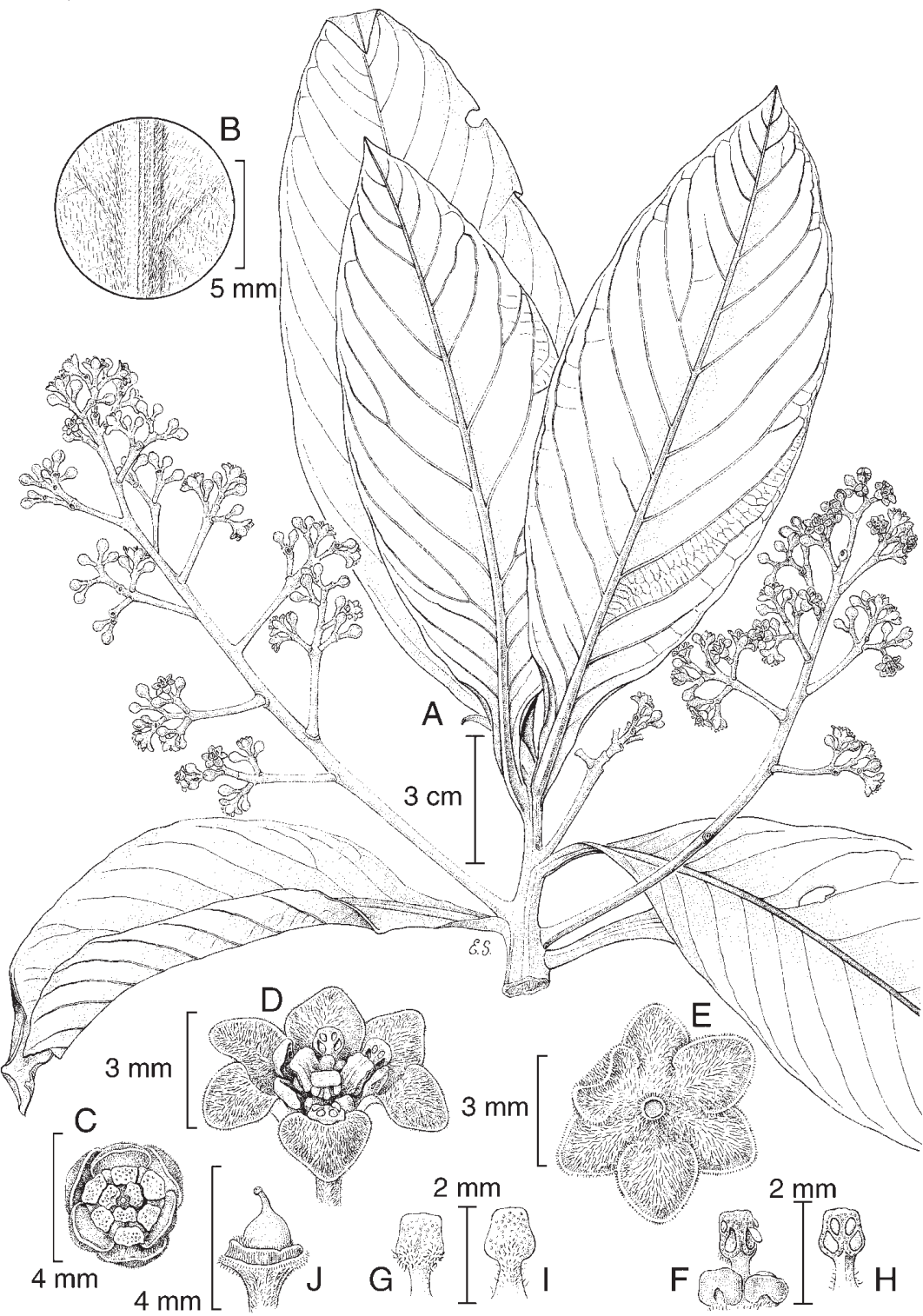
manifesto, hypanthio non profundo, extus dense pubescenti, intus leviter sericeo, pistillo glabro; fructibus ignotis.

Árboles de hasta $20 \mathrm{~m}$; ramillas ligeramente estriadas, densamente pubescentes o cortamente tomentosas, los tricomas de $0.3(-0.5) \mathrm{mm}$, pardo amarillos; peciolo de 11-15 x 2.8-3.5 mm, aplanado, marginado, pubescente del mismo modo que las ramillas; lámina foliar de $15-23$ x 5-9 cm, elíptica, ápice agudo a ligeramente acuminado, base atenuada, sus márgenes ligera pero conspicuamente revolutos, superficie adaxial glabra, superficie abaxial ligeramente glauca, esparcidamente seríceo pubescente, glabrescente hacia los márgenes al envejecer, vena media plana a ligeramente hundida del lado adaxial, glabra, elevada del abaxial, seríceo pubescente, venas secundarias 12-15 pares, planas adaxialmente, glabras, algo elevadas abaxialmente, seríceo pubescentes, venas terciarias planas adaxial y abaxialmente, esparcidamente seríceo pubescentes del lado abaxial, domacios ausentes, pero con frecuencia las axilas de las venas secundarias en los pares basales con tricomas sinuosos entrelazados; inflorescencias de $12-20 \mathrm{~cm}$ de largo, axilares a las hojas, tirso-paniculadas, densamente pubescentes a cortamente tomentosas, los tricomas pardo amarillentos, pedúnculo de 4-6 cm, los ejes terciarios y subsecuentes comprimidos, pedicelo de (1.3-)2-3 mm, densamente pubescente a tomentoso; flores rotadas, tépalos externos de 2.3-2.7 x 2.2-2.5 mm, ampliamente ovados, densamente pubescentes adaxial y abaxialmente, tépalos internos de 2.1$2.3 \times 1.6-2 \mathrm{~mm}$, ovados, densamente pubescentes adaxial y abaxialmente, estambres de los verticilos I y II de 1.2-1.5 mm, filamentos esparcidamente pubescentes a lo largo de su parte media del lado adaxial, pubescentes abaxialmente, anteras de casi $0.8 \mathrm{~mm}$, glabras adaxialmente, pubescentes en la base abaxialmente, esporangios cuatro, dispuestos en un arco ligero, introrsos, estambres del verticilo III de 1.5$1.7 \mathrm{~mm}$, filamentos glabros adaxialmente, glabros o glabrescentes abaxialmente, anteras de casi $0.8 \mathrm{~mm}$, glabras excepto su base que es híspido pubescente adaxialmente, esporangios cuatro, los basales extrorsos, los superiores latrorsos, glándulas de 0.5-0.7 mm, en la base del filamento, glabras, estaminodios de casi $0.7 \mathrm{~mm}$, claviformes, por lo común sólo uno presente, los otros dos reducidos a protuberancias diminutas o ausentes, glabros del lado adaxial, pubescentes del abaxial, hipantio de $0.8 \mathrm{~mm}$ de profundidad, densamente pubescente abaxialmente, los tricomas pardo amarillos, esparcidamente seríceo pubescente a glabrescente adaxialmente, pistilo de casi $2.5 \mathrm{~mm}$ de largo, glabro, ovario de casi $1.2 \times 1.2$ $\mathrm{mm}$; fruto maduro desconocido, tépalos no persistentes, deciduos.

Hasta ahora Ocotea zoque es conocida por una sola colecta en la localidad tipo, alrededor de los $1650 \mathrm{~m}$ s.n.m. En esta zona predominan condiciones húmedas de montaña y las comunidades corresponden, en sentido amplio, a bosques mesófilos 
de montaña creciendo sobre sustrato cárstico. Sea por la geología o alguna condición climática particular, elementos de tierras más cálidas acompañan a $O$. zoque en el estrato arbóreo superior, destacando Coccoloba y Ficus, mezcladas con Alchornea, Clethra, Persea y Quercus. La fuerte afectación de esta parte boscosa de Oaxaca por los incendios de 1998, ha puesto bajo gran riesgo la persistencia de varias especies endémicas a este tipo de hábitat tan peculiar que es el carst; Ocotea zoque con seguridad es una de estas especies amenazadas.

Ocotea zoque es un taxon más a considerar en el grupo de $O$. insularis (Rohwer, 1986; van der Werff, 2002a). La característica distribución de la pubescencia en los estambres y los ejes comprimidos de las inflorescencias en esta especie, constatan tal relación. Las especies más cercanas a $O$. zoque son $O$. chiapensis y $O$. glaucosericea Rohwer. La primera, que se encuentra en el sur de México y Guatemala, se distingue de $O$. zoque por presentar tallos, hojas y flores (externamente) que son menos pubescentes, y domacios (pequeñas áreas modificadas de la superficie inferior de las hojas conformadas por una sección elíptica de la lámina, glabra, rodeada por numerosos tricomas en el borde) evidentes cerca de la axila de las venas secundarias; la segunda, una especie de Costa Rica y Panamá, se distingue por tener una pubescencia en tallos hojas y flores semejante a la de $O$. zoque, pero las hojas son obovadas a oblanceoladas, redondeadas a obtusas en el ápice y con 5 a 9 pares de venas secundarias. En tanto, las hojas de $O$. zoque son elípticas, con el ápice agudo a levemente acuminado, sin domacios (a lo más con algunos mechones de tricomas en las axilas de las venas secundarias basales, no asociados a secciones modificadas de la lámina), y con 12 a 19 pares de venas secundarias. El nombre de la especie honra la cultura ancestral que ha prevalecido en esa región de Oaxaca donde fue colectada.

Persea chrysantha Lorea-Hern. sp. nov. Fig. 7.

Tipo. México. Guerrero: mpio. Leonardo Bravo, $6 \mathrm{~km}$ al NW de Cruz de Ocote, 2200 m, 12 marzo 1983, E. Velázquez 201 (holotipo, XAL, isotipos, FCME, MEXU, MO).

Arbores; ramulis glabris; foliis anguste ellipticis vel ellipticis, in apice acutatis vel acuminatis, base cuneatis, interdum obliquis, laminis supra et infra glabris; inflorescentiis thyrsoideis, tomentosis, sed ad pedunculum glabris; floribus campanulatis, tepalis inaequalibus, extus tomentosis, externis brevibus, intus glabris, internis longis, intus pubescentibus, staminibus novem, tetrasporangiatis, pistillo glabro; fructibus ignotis. 


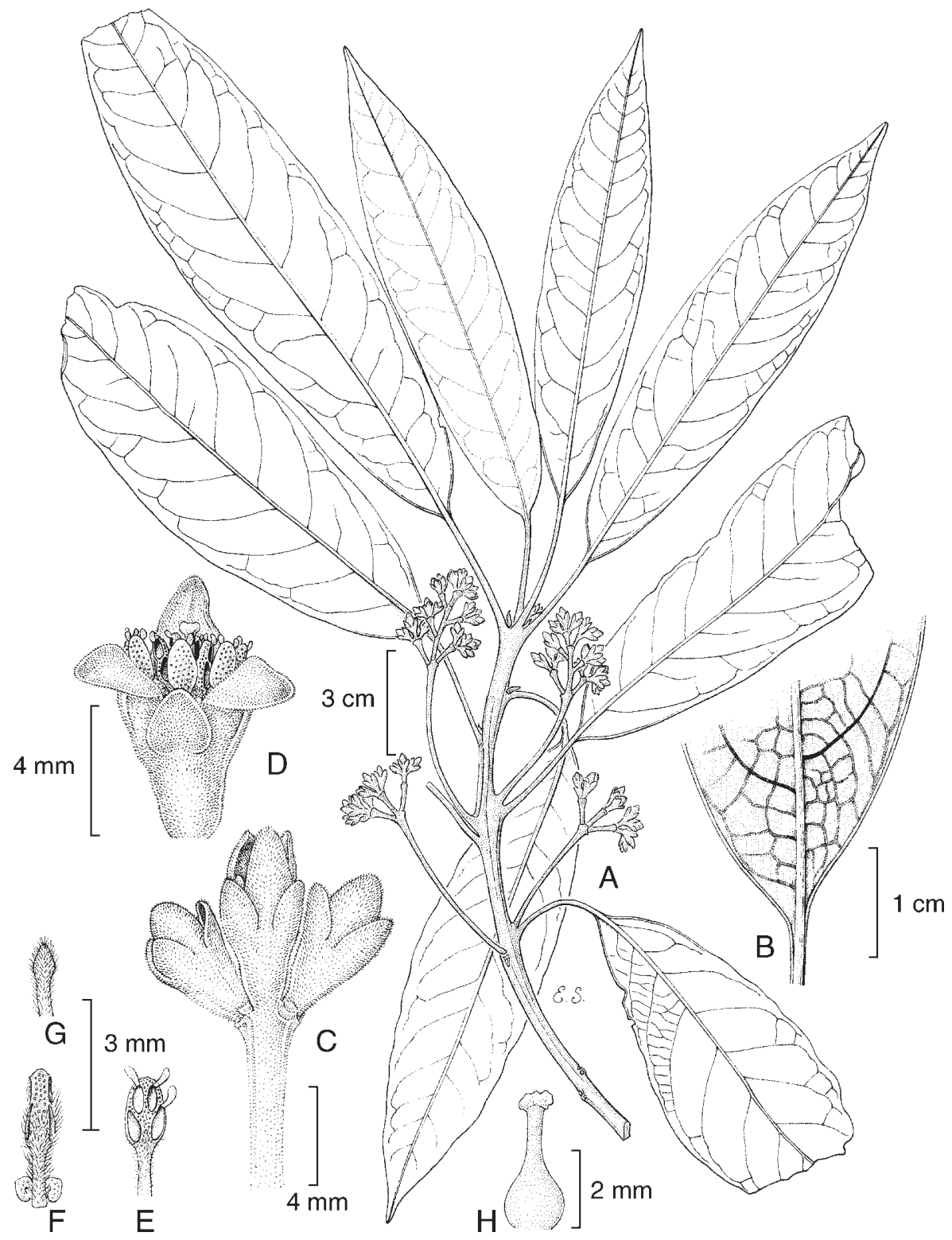

Fig. 7. Persea chrysantha. A. Ramilla con inflorescencias; B. Detalle del envés de la hoja; C. Detalle de la inflorescencia; D. Vista lateral de una flor; E. Vista adaxial de un estambre externo; F. Vista abaxial de un estambre interno; G. Estaminodio; H. Pistilo. 
Árboles de 7-18 m; ramillas algo acostilladas, angulosas, al menos cuando secas, pardo rojizas, glabras, catafilos de las yemas seríceo pubescentes, al menos en sus márgenes; peciolo de (25-)30-40(-45) x (1.2-)1.5-1.8 mm, más o menos rollizo a cuadrangular, glabro; lámina foliar de 11.5-17(-22) x (2.5-)3.5-5.5(-7) cm, angostamente elíptica o elíptica, en ocasiones obovada u oblanceolada, ápice agudo a acuminado, base cuneada, a veces oblicua, superficies adaxial y abaxial glabras, vena media plana o ligeramente hundida del lado adaxial, glabra, fuertemente elevada del lado abaxial, glabra, venas secundarias (10-)11-13(-14) pares, planas adaxialmente, glabras, algo elevadas abaxialmente, glabras, venas terciarias planas y glabras adaxial y abaxialmente; inflorescencias de $(2.5-) 4-6(-8.5) \mathrm{cm}$, axilares a las hojas, tirsoides, en ocasiones tirso-paniculadas, ejes y partes externas de las flores con pubescencia de color pardo dorado, pedúnculo de (1.5-)3-4.5(-6) cm, glabro en toda su extensión o seríceo tomentoso en el extremo distal, raquis y ejes secundarios seríceo tomentosos, pedicelo de 2-2.5 mm, seríceo tomentoso; flores campanuladas, tépalos dimorfos, los externos de 2.5-3 x 2.5-2.8 mm, ampliamente ovados, seríceo tomentosos abaxialmente, glabros adaxialmente, los internos de 5.26 x 2.5-3 mm, ovados, seríceo tomentosos del lado abaxial, densamente pubescentes del adaxial, estambres de los verticilos I y II de casi $3.5 \mathrm{~mm}$, filamentos pubescentes adaxialmente, en toda la superficie o sólo a lo largo de la parte central, densamente pubescentes del lado abaxial, anteras de casi $2 \mathrm{~mm}$, pubescentes en la mitad inferior del conectivo adaxial y abaxialmente, esporangios cuatro, angostamente elípticos, introrsos, estambres del verticilo III de 4-4.2 mm, filamentos glabros en su mitad inferior y densamente pubescentes en su mitad distal del lado adaxial, densamente pubescentes del lado abaxial, anteras de 1.8-2 $\mathrm{mm}$, densamente pubescentes en su mitad inferior adaxialmente, pubescente a lo largo del conectivo en su mayor parte abaxialmente, esporangios cuatro, angostamente elípticos, latrorsos, glándulas de casi $0.9 \mathrm{~mm}$, cortamente pediceladas, el pedicelo pubescente, insertas por arriba de la base del filamento, obcordadas, glabras, estaminodios del verticilo IV de 1.6-1.8 $\mathrm{mm}$, filamento glabro del lado adaxial, densamente pubescente del abaxial, ápice de 0.6-0.8 $\mathrm{mm}$, ovado triangular, glabro adaxialmente, densamente pubescente abaxialmente, hipantio de casi $0.2 \mathrm{~mm}$ de largo, seríceo por fuera, glabrescente por dentro, casi plano, pistilo de $4-4.5 \mathrm{~mm}$, glabro, ovario de 1.8$2.2 \mathrm{~mm}$ de largo; fruto desconocido.

Persea chrysantha es una especie que habita los bosques mesófilos y de encino húmedos de un área reducida del centro del estado de Guerrero en la Sierra Madre del Sur. Comparte el estrato arbóreo con especies de los géneros Alnus, Licaria, Pinus y Quercus, cerca de los $2200 \mathrm{~m}$ de altitud. Al parecer, P. chrysantha no es una planta común, ya que en estudios ecológicos intensivos recientes muy cerca de la localidad tipo, no fue encontrada. 
Paratipo. México. Guerrero: mpio. Leonardo Bravo, aprox. $3 \mathrm{~km}$ al NE de Cruz de Ocote, (fl.), F. Lorea 4190 (XAL).

Las características vegetativas de Persea chrysantha señalan una aparente relación con especies cercanas a $P$. liebmannii Mez, en particular con $P$. standleyi C. K. Allen y $P$. longipes (Schltdl.) Meissn. por las dimensiones de sus hojas, largo del peciolo, así como la presencia de ramas, peciolos y hojas maduros glabros (o glabrescentes). Sin embargo, tanto en $P$. standleyi como en $P$. longipes las ramas y hojas en desarrollo son siempre más o menos pubescentes, con pelos rectos adpresos, el mismo tipo de tricomas que presentan los ejes de sus inflorescencias y flores. En $P$. chrysantha, en cambio, los tallos y hojas son glabros desde el principio y la pubescencia de sus inflorescencias y flores no es adpresa. Esta característica apunta más bien a una relación con $P$. hintonii C. K. Allen, la especie de Persea de mayor distribución en el occidente de México. $P$. chrysantha y $P$. hintonii son semejantes en la forma y tamaño de las hojas, así como en la longitud de sus peciolos y la estructura y tipo de pubescencia en las inflorescencias, pero difieren en que la primera, excepto las inflorescencias, es totalmente glabra, tiene flores más grandes (hasta $6 \mathrm{~mm}$ de largo) y habita en sitios de mayor altitud (ca. 2200 m s.n.m.), mientras que la segunda, siempre es conspicua y persistentemente pubescente en sus ramas y hojas, posee flores menores (ca. $4.5 \mathrm{~mm}$ de largo) y habita zonas de elevación intermedia (600 a 1700 m s.n.m.).

Los rasgos morfológicos de Persea chrysantha (tépalos desiguales, los externos glabros en su cara adaxial, estambres del verticilo III con cuatro esporangios y pistilo glabro) la ubican dentro del subgénero Eriodaphne sección Eriodaphne (Kopp, 1966). Si bien no se conocen los frutos de la planta en cuestión, es de esperarse con seguridad que sean esféricos (de 1-1.5 cm de diámetro) y con los tépalos persistentes en su base. Del color pardo dorado de las flores deriva el nombre de esta nueva especie.

Persea obscura Lorea-Hern. sp. nov. Fig. 8.

Tipo. México. Oaxaca: mpio. San Miguel Chimalapa, $5.9 \mathrm{~km}$ en línea recta al NW de Benito Juárez, 16²4'10.5" N, 94¹1'45.3" W, 1700 m, 25 julio 2001, C. Gallardo, N. Velázquez, R. López, S. Jiménez, P. López y V. Sánchez 2675 (holotipo, XAL, isotipos, MEXU, MO).

Arbores; ramulis glabris; foliis ellipticis vel anguste ellipticis, in apice acuminatis vel caudatis, base cuneatis vel obtusatis, supra et infra glabris; inflorescentiis thyrsoideis, glabris; floribus anguste urceolatis, tepalis (sub)aequalibus, extus glabris, intus sericeis, persistentibus in fructu, staminibus novem, tetrasporangiatis, 


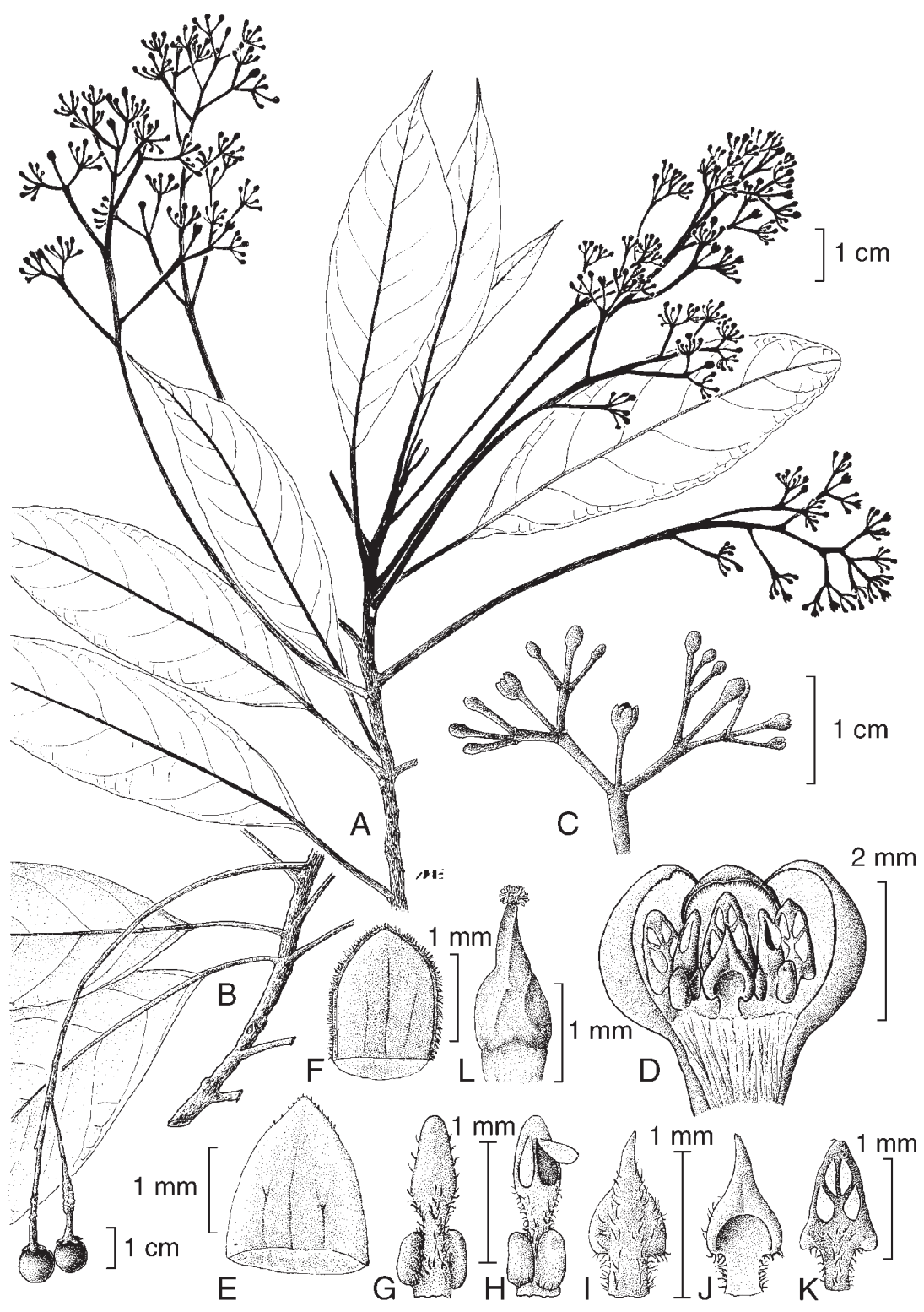

Fig. 8. Persea obscura. A. Ramilla con flores; B. Detalle de una ramilla con frutos; C. Detalle de la inflorescencia; D. Vista interior de una flor; E. Vista abaxial de un tépalo externo; F. Vista abaxial de un tépalo interno; G. Vista adaxial de un estambre interno; H. Vista abaxial de un estambre interno; I. Vista abaxial de un estaminodio; J. Vista adaxial de un estaminodio; K. Vista adaxial de un estambre externo; L. Pistilo. 
sed tertii verticilli bisporangiatis, pistillo glabro; fructibus sphaericis, tepalis in fructuum persistentibus, pedicellis accrescentibus, incrassatis, lenticellatis.

Árboles de 12-20 m; ramillas glabras; peciolo de (11-)15-25(-35) x 0.7$1.4 \mathrm{~mm}$, glabro; lámina foliar de (7-)10-15(-18.5) x (1.5-)3-4.5(-6) cm, elíptica o angostamente elíptica, base cuneada o a veces obtusa, ápice acuminado a caudado, haz glabra, envés glabro, vena media plana hacia la base y ligeramente elevada hacia el ápice del lado adaxial, glabra, elevada del lado abaxial, glabra, venas secundarias (7-)8-10(-11) pares, planas en la haz, glabras, planas en el envés, glabras, venas terciarias planas y glabras en ambas superficies; inflorescencia de $13-20 \mathrm{~cm}$ de largo, en la axila de las hojas o, a veces, en la axila de brácteas deciduas en la base de los brotes nuevos, tirsoide, pedúnculo de $7.5-10.5 \mathrm{~cm}$ de largo, glabro, los otros ejes de la inflorescencia también glabros, pedicelo floral de 4-6 mm de largo, glabro; flores angostamente urceoladas, tépalos de 2.1-2.5 x 1.4-1.8 mm, ovados, los externos glabros por fuera y esparcidamente seríceos por dentro, sobre todo en la base, los internos glabros o con unos pocos tricomas por fuera, seríceos por dentro, estambres de los verticilos I y II de 1.6-1.8 mm de largo, filamentos glabros o esparcidamente pilosos a lo largo de la línea media del lado adaxial, con el mismo tipo de pubescencia del lado abaxial, anteras de casi $1 \mathrm{~mm}$ de largo, a veces ligeramente hastadas, glabras, esporangios cuatro, en dos pares, introrsos, estambres del verticilo III de 1.8-1.9 mm de largo, filamentos esparcidamente pilosos en sus márgenes, con una línea media de tricomas en la superficie adaxial, esparcidamente pilosos a glabros en la abaxial, anteras de casi $1 \mathrm{~mm}$ de largo, glabras, esporangios dos (los basales), a veces los superiores presentes pero diminutos, glándulas de $0.6 \mathrm{~mm}$ de largo, oblongas, glabras, estaminodios de $1.4 \mathrm{~mm}$ de largo, filamento glabro del lado adaxial y abaxial, esparcidamente piloso en sus márgenes, ápice de $1 \mathrm{~mm}$ de largo, obcordado, acuminado, glabro del lado adaxial, esparcidamente piloso hacia los márgenes del lado abaxial, hipantio de casi $0.2 \mathrm{~mm}$ de largo, casi plano, glabro por fuera y por dentro, pistilo de $2-2.2 \mathrm{~mm}$ de largo, glabro, ovario de 1-1.2 mm de largo; fruto de 10-13 mm, esférico, asentado en el hipantio no agrandado, tépalos persistentes en el fruto maduro, extendidos, ligeramente agrandados y engrosados, pedicelo engrosado y alargado, de $15-25 \mathrm{~mm}$ de largo, de 3.5-4.5 $\mathrm{mm}$ de ancho en su parte apical y de 1.2-1.5 $\mathrm{mm}$ de ancho en su parte basal, leñoso, con numerosas lenticelas.

Esta especie hasta ahora es conocida de los bosques mesófilos de San Miguel Chimalapa, cuyas comunidades son dominadas por Ticodendron incognitum, Ternstroemia aff. seemannii y Symplococarpon purpusii. Otros elementos del dosel lo constituyen especies de los géneros Alchornea, Matayba, Persea, Weinmannia y Zanthoxylum. Florece en la primavera (abril) y presenta frutos 
maduros de marzo a julio. Persea obscura se encuentra entre los 1400 y los 1700 m s.n.m.

Paratipos. México. Oaxaca: mpio. San Miguel Chimalapa, $5.9 \mathrm{~km}$ en línea recta al NW de Benito Juárez, (fl.), C. Gallardo et al. 2501 (XAL); Campamento Perdiz, aprox. $2.5 \mathrm{~km}$ al W de Díaz Ordaz, (fr.), E. Torres et al. 1195 (XAL); (fr.), J. Rivera et al. 273 (XAL); (fr.), J. Rivera et al. 285 (XAL).

Las relaciones de Persea obscura con las especies del área mesoamericana no son claras. La posesión de características por demás singulares como los estambres del verticilo III con sólo dos esporangios, los tépalos (sub)iguales pubescentes en su cara adaxial y persistentes, así como el pedicelo acrescente y engrosado llevando el fruto, la colocan fuera de cualquiera de las secciones reconocidas para el género en América (Kopp, 1966). En algún modo, se relaciona con el "grupo 4" (de cualidades que se corresponden con el género asiático Alseodaphne) sugerido por van der Werff (2002b) en su reciente revisión del género para Centroamérica, excepto porque $P$. obscura no presenta hojas hacinadas en el extremo de las ramas. Ciertamente, como señala van der Werff (op. cit.), es probable que una revisión moderna del género cambie de manera radical los conceptos taxonómicos dentro de Persea. Eventualmente se puede hallar que $P$. obscura, junto con otras especies que en la actualidad tampoco tienen cabida en el esquema taxonómico en uso, tengan relaciones más estrechas entre sí y a su vez, con grupos que están mejor representados en el hemisferio oriental. El epíteto específico se debe a la consideración de la falta de elementos para asignar a este nuevo taxon una posición dentro de las especies conocidas del área.

\section{AGRADECIMIENTOS}

El autor agradece a Jorge Meave, Armando Rincón y Claudia Gallardo el envío del material que ha constituido la base para la descripción de varias de las especies aquí reconocidas. A Henk van der Werff la revisión crítica y detallada del manuscrito. A Manuel Escamilla y Edmundo Saavedra la excelente ejecución de las figuras que complementan las descripciones de los nuevos taxones.

\section{LITERATURA CITADA}

Kopp, L. E. 1966. A taxonomic revision of the genus Persea in the western hemisphere (Perseae-Lauraceae). Mem. New York Bot. Gard. 14: 1-120. 
Kurz, H. 2000. Revision der Gattung Licaria (Lauraceae). Mitt. Inst. Allg. Bot. Hamburg 28/29: 89-221.

Rohwer, J. G. 1986. Prodromus einer Monographie der Gattung Ocotea Aubl. (Lauraceae) sensu lato. Mitt. Inst. Allg. Bot. Hamburg 20: 1-278.

Rohwer, J. G. 1991. Borderline cases between Ocotea, Nectandra, and Phoebe (Lauraceae): The "marginal" species of the Ocotea helicterifolia-group, including the $O$. heydeana-group. Bot. Jahrb. Syst. 112: 365-397.

van der Werff, H. 2002a. A synopsis of Ocotea (Lauraceae) in Central America and southern Mexico. Ann. Missouri Bot. Gard. 89: 429-451.

van der Werff, H. 2002b. A synopsis of Persea (Lauraceae) in Central America. Novon 12: 575-586.

Recibido en febrero de 2004. Aceptado en diciembre de 2004. 